\title{
Community genetics. Its definition 2010
}

\author{
Leo P. ten Kate • Lihadh Al-Gazali • Sonia Anand • Alan Bittles • \\ Jean-Jacques Cassiman • Arnold Christianson • Martina C. Cornel • \\ Hanan Hamamy • Helena Kääriäinen • Ulf Kristoffersson • David Marais • \\ Victor B. Penchaszadeh • Proton Rahman • Jörg Schmidtke
}

Received: 17 January 2010 / Accepted: 10 March 2010/Published online: 31 March 2010

(C) The Author(s) 2010. This article is published with open access at Springerlink.com

\begin{abstract}
This paper presents a definition of the medical field of community genetics. It starts with a brief historical overview, defines the requirements for an adequate definition, presents the definition, and discusses the constituent parts of the definition.
\end{abstract}

\section{Introduction}

The term community genetics originated separately in biology and medicine.

\section{P. ten Kate $\cdot$ M. C. Cornel}

VU University Medical Center,

Amsterdam, The Netherlands

\section{Al-Gazali}

Faculty of Medicine and Health Sciences,

UAE University,

Al Ain, United Arab Emirates

\section{S. Anand}

McMaster University,

Hamilton, Canada

\author{
A. Bittles \\ Centre for Comparative Genomics, Murdoch University, \\ Perth, Australia
}

J.-J. Cassiman

Center for Human Genetics, Campus Gasthuisberg, KULeuven,

Leuven, Belgium
A. Christianson
of the Witwatersrand,
Johannesburg, South Africa
H. Hamamy
Geneva University Hospital,
Geneva, Switzerland

National Health Laboratory Service and University
Community genetics is a field of research within biology, analysing evolutionary genetic processes that occur among interacting populations in communities. The term emerged in a discussion between Jim Collins from Arizona State University and Janis Antonovics from Duke University in the early 1980s, and it was Antonovics who introduced the concept into scientific literature in 1992 (Antonovics 1992; Collins 2003). Since that time the field has become recognized with the term community genomics as a more recent innovation (Antonovitz 2003; Neuhauser et al. 2003; Whitham et al. 2003). Our present paper will

\section{H. Kääriäinen}

National Institute for Health and Welfare,

Helsinki, Finland

U. Kristoffersson

University and Regional Laboratories, University Hospital,

Lund, Sweden

D. Marais

Groote Schuur Hospital and University of Cape Town Health

Science Faculty,

Cape Town, South Africa

V. B. Penchaszadeh

Columbia University,

New York, USA

\section{P. Rahman}

Memorial University,

St. John's, Newfoundland, Canada

J. Schmidtke

Hannover Medical School,

Hannover, Germany

L. P. ten Kate $(\bowtie)$

Department of Clinical Genetics, VU University Medical Center, BS7 D422, P.O. Box 7057, 1007 MB Amsterdam,

The Netherlands

e-mail: lp.tenkate@vumc.nl 
not further consider the biological version of community genetics.

In medicine the term community genetics emerged from work within the World Health Organization on community genetics services. The initial document with this title, combining community with genetic services, dates from 1987 (mentioned in Modell et al. 1991). The term community genetics without the appended 'services' was first used in 1990 (Modell 1990; Modell and Kuliev 1998). Unlike community genetics in biology, community genetics in medicine did not start as a field of research but focused on service delivery. Nevertheless, the need for a science of community genetics was immediately recognized (Modell 1992; Modell and Kuliev 1993).

A second landmark in the history of community genetics was the appearance in 1998 of a journal bearing that title, published by Karger AG (Ten Kate 1998). The journal emphasized a critical attitude toward goals and terminology concerning the prevention and control of genetic diseases, instead concentrating on respect for autonomy and reproductive choice. This move can be explained by the professional background of the founder and editor-in-chief (clinical genetics) and associate editors, and by their ties with parent-and-patient organizations. The large-scale application of genetics to disease prevention can easily be confused with eugenic practices of the type seen in western countries during the early twentieth century. To "improve the gene pool", some people were forbidden to procreate while the fittest were encouraged to have many children. To avoid moral pitfalls, respect for autonomy and informed choices in reproductive decisions became the ethical cornerstones of clinical genetics (Biesecker 2001) and from the start they were integrated within community genetics. In the case of primary prevention, for instance by avoiding exposure to radiation or by providing folic acid supplementation to prevent neural tube defects, the aim of community genetics represents a straightforward public health goal to reduce the burden of disease. In the case of decisions whether or not to procreate or whether or not to use prenatal diagnosis and selective abortion, informed choice may, however, conflict with a public health goal to reduce disease prevalence.

Cooperation with a parent-and-patient association in promoting the concept of community genetics was also at stake in the organization of the first international conference on community genetics, held in Jonquière, Canada, 2000 (Gaudet 1999). Of course the early writers on community genetics did their best to define the concept as correctly as possible (Ten Kate 1998, 1999; Gaudet 1999; Brisson 2000). Concepts and definitions, however, are not only determined by their early users; their final form is honed in response to criticism and misinterpretations by others. These critiques, misinterpretations, and the resulting polemics can be found in the literature (Khoury et al. 2000;
Ten Kate 2000, 2005, 2008; Brand 2005; Mackenbach 2005; Stewart et al. 2007; Knoppers and Brand 2009). So it is appropriate that our present definition should be adapted to reflect the current state of affairs.

What other requirements should be met to arrive at a first-rate definition of a medical field? First, the definition should be broad enough to include all the activities and areas of interest of those who regard themselves as workers in that particular field. Secondly, the definition should be sufficiently restrictive to differentiate the field from adjacent topic areas. Table 1 gives an inventory of activities and areas of interest within the field of community genetics. Table 2 shows a list of adjacent fields that should be differentiated from community genetics.

\section{Definition}

Community genetics is the art and science of the responsible and realistic application of health and disease-related genetics and genomics knowledge and technologies in human populations and communities to the benefit of individuals therein. Community genetics is multi-, inter- and transdisciplinary and aims to maximize benefits while minimizing the risk of harm, respecting the autonomy of individuals and ensuring equity.

\section{Discussion}

Where the definition starts with "Community Genetics" one also can read "Community Genomics". We choose the single term community genetics for the sake of simplicity; and since there are more possibilities for the implementation of genetics than genomics in the community at present (Janssens and Van

Table 1 Activities and areas of interest within the field of community genetics

Genetic screening

Genetic literacy/education

Access and quality of genetic services

Genetics in primary care

Genetics in middle and low income countries

Genetics in disadvantaged subpopulations

Registries of congenital and genetic disorders

Genetics in preconception care

Public consultation about genetic issues

Epidemiologic issues

Economic issues

Psychosocial issues

Ethical and legal issues

Policy issues 
Table 2 Adjacent fields that should be differentiated from community genetics

Clinical genetics

Population genetics or genomics

Genetic epidemiology

Public health genetics or genomics

Duijn 2008). Moreover, it is felt that genomics is not an alternative to genetics but rather a specialist sub-branch.

The definition includes both application (the art) and research (science) in developing new applications or assessing the effects of existing applications. Applications should be responsible, requiring ethical, legal, and societal justification; and they should be realistic, setting them apart from hype and exaggerated expectations.

Community genetics involves genetics and genomics knowledge and technology, but it is restricted to health and disease, thereby excluding interventions on normal physical or behavioural variation.

The application is directed at human populations, which distinguishes it from community genetics in the biological sense. The targets of community genetics are encompassing more than an individual person, couple or family. Communities can be defined according to different characteristics (Table 3).

Although targeting communities the benefit should be for the individual person and couple (Modell and Kuliev 1993). Economic gains or eugenic aims are not the goal of community genetics. Even public health is not a primary goal, if interpreted solely as the reduction of the burden of disease. Especially for reproductive choices such as a decision (not) to procreate, or (not) to use prenatal diagnosis and selective abortion, it is important to distinguish the goal (to facilitate informed choice) from the possible consequence (reducing live birth prevalence). Optimal psychosocial wellbeing may better be served by informed choice than by forcing people to participate in programs that do not conform to their personal beliefs and moral stances. Promoting informed reproductive decision-making does not, however, exclude substantial secondary beneficial consequences for public health, health economics or changes in gene frequencies, which ultimately also may be of benefit at the individual level. Maximizing benefit, minimizing harm, respect for privacy and autonomy and ensuring equity are all in accord with this focus on the benefit to individual persons.

Community genetics is not just a sub-discipline of genetics, as many disciplines are working together within the field. This collaboration may be side-by-side without significant interaction as sometimes happens in scientific studies (multidisciplinary), involving interaction between disciplines (interdisciplinary) or even crossing traditional boundaries between disciplines (transdisciplinary) as fre- quently occurs in the application of genetics at the community level (Rowland 2006).

It is clear that the definition does accommodate all of the activities and interests currently regarded as being a part of community genetics (Table 1). At first sight, it seems that Modell (1992) listed several additional items. However, on closer examination, they are in fact included under headings shown in Table 1. Liaison with support organizations is part of public consultation, and liaison with health authorities to ensure the delivery of appropriate genetic services is included in policy issues. Audit intended to monitor service delivery is part of epidemiological issues, together with descriptive epidemiology and research to identify community needs. Audit to analyse costs and benefits is included within economic and psychosocial issues.

Although benefit to the individual is central to both community genetics and clinical genetics, community genetics seeks to locate people within the wider community who may be at increased risk of a genetic problem, but have not yet been identified or helped. Whereas clinical geneticists deal with persons or families with a particular problem or concern who have requested or been referred for a consultation.

Population genetics or genomics is interested primarily in the distribution of allele frequencies and the mechanisms underlying this distribution. Genetic epidemiology focuses on understanding the role of genetics or genomics in the occurrence and recurrence of disease. Both disciplines provide essential knowledge for the successful delivery of community genetics services. Of course the same applies to clinical genetics.

Public health genetics and genomics and community genetics and genomics have much in common but differ in their principal aim (public health vs. benefit of the individual person), the ability to deal with sensitive issues, such as reproduction and presymptomatic diagnosis, and an interest in small communities and rare diseases (Ten Kate 2008). Whether the differences between public health genetics or genomics and community genetics or genomics are a question of emphasis or represent a genuine point of principle is a matter for debate..

Table 3 Types of communities

Defined geographically

e.g. village, town, region, country

Defined by origin

e.g. African and Asian immigrants in Europe

Defined by culture, religion or socio-economic characteristics

e.g. Roma, Irish travelers

Defined by common problem

e.g. prevalent disease, specific risk 
In summary, the authors believe that the proposed definition is appropriate and will assist in the promotion of the art and science required for humans and their communities. The affiliations of the authors are only given for the purpose of identification, and do not mean that their views necessarily represent the views of their institution.

Open Access This article is distributed under the terms of the Creative Commons Attribution Noncommercial License which permits any noncommercial use, distribution, and reproduction in any medium, provided the original author(s) and source are credited.

\section{References}

Antonovics J (1992) Toward community genetics. In: Fritz RS, Simms EL (eds) Plant resistance to herbivores and pathogens: ecology, evolution and genetics. University of Chicago Press, Chicago and London

Antonovitz J (2003) Toward community genomic? Ecology 84:598-601

Biesecker BB (2001) Goals of genetic counseling. Clin Genet 60:323-330

Brand A (2005) Public Health and genetics - a dangerous combination? Eur J Publ Health 15:114-116

Brisson D (2000) Analysis and integration of definitions of community genetics. Community Genet 3:99-101

Collins JP (2003) What can we learn from community genetics? Ecology 84:574-577

Gaudet D (1999) From DNA to the community. Community Genet 2:139-140

Janssens ACJW, Van Duijn CM (2008) Genome-based prediction of common diseases: advances and prospects. Hum Mol Genet 17 (R2):R166-R173

Khoury MJ, Burke W, Thomson EJ (2000) Genetics and public health: A framework for the integration of human genetics into public health practice. In: Khoury MJ, Burke W, Thomson EJ (eds) Genetics and public health in the 21 st century. Using genetic information to improve health and prevent disease. Oxford Monographs on Medical Genetics. Oxford, Oxford University Press, vol. 40

Knoppers BM, Brand AM (2009) From community genetics to public health genomics - what's in a name? Publ Health Genomics $12: 1-3$

Mackenbach JP (2005) Community genetics or public health genetics? J Epidemiol Community Health 59:179-180

Modell B (1990) Cystic fibrosis screening and community genetics. J Med Genet 27:475-479

Modell B (1992) The need for a science of community genetics. Birth Defects Orig Artic Ser 28(3):131-141

Modell B, Kuliev AM (1993) A scientific basis for cost-benefit analysis of genetic services. Trends Genet 9:46-52

Modell B, Kuliev A (1998) The history of community genetics: the contribution of the haemoglobin disorders. Community Genet $1: 3-11$

Modell B, Kuliev AM, Wagner M (1991) Community genetics services in Europe: report on a survey. WHO Regional Publications, European Series, No. 38

Neuhauser C, Andow DA, Heimpel G, May G, Shaw R, Wagenius S (2003) Community genetics: expanding the synthesis of ecology and genetics. Ecology 84:545-558

Stewart A, Brice P, Burton H, Pharao P, Sanderson S, Zimmern R (2007) Genetics, Health Care and Public Policy. An Introduction to Public Health Genetics. Cambridge University Press

Rowland S (2006) The Enquiring University, McGraw Hill

Ten Kate LP (1998) Editorial. Community Genet 1:1-2

Ten Kate LP (1999) The concept of community genetics (abstract). Community Genet 2:152

Ten Kate LP (2000) Editorial. Community Genet 3:1

Ten Kate LP (2005) Community Genetics: a bridge between clinical genetics and public health. Community Gene 8:7-11

Ten Kate LP (2008) Community genetics in the era of public health genomics. Community Genet 11:1

Whitham TG, Young WP, Martinsen GD, Gehring CA, Schweitzer JA, Shuster SM, Wimp GM, Fischer DG, Bailey JK, Lindroth RL, Woolbright S, Kuske CR (2003) Community and ecosystem genetics: a consequence of the extended phenotype. Ecology $84: 559-573$ 